\title{
Rethinking economic capital management through the integrated derivative-based treatment of interest rate and credit risk
}

\author{
Mariya Gubareva ${ }^{1,2}$ (D) Maria Rosa Borges $^{2,3}$ (D)
}

(C) Springer Science+Business Media New York 2017

\begin{abstract}
This research revisits the economic capital management regarding banking books of financial institutions exposed to the emerging market sovereign debt. We develop a derivative-based integrated approach to quantify economic capital requirements for considered jointly interest rate and credit risk. Our framework represents a major contribution to the empirical aspects of capital management. The proposed innovative modeling allows applying standard historic value-at-risk techniques developed for stand-alone risk factors to evaluate aggregate impacts of several risks. We use the time-series of credit default swap spreads and interest rate swap rates as proxy measures for credit risk and interest rate risk, respectively. An elasticity of interest rate risk and credit risk, considered a function of the business cycle phases, maturity of instruments, creditworthiness, and other macroeconomic parameters, is gauged by means of numerical modeling. Our contribution to the new economic thinking regarding the interest rate risk and credit rate risk management consists in their integrated treatment as the dynamics of interest rate and credit spreads is found to demonstrate the features of automatic stabilizers of each other. This research sheds light on how financial institutions may address hedge strategies against downside risks. It is of special importance for emerging markets heavily dependent on foreign capital as it potentially allows emerging market banks to improve risk management practices in terms of capital adequacy and Basel III rules. From the regulatory perspective, by taking into account inter-risk diversification effects it allows enhancing financial stability through jointly optimizing Pillar 1 and Pillar 2 economic capital.
\end{abstract}

Mariya Gubareva

mgubareva@iscal.ipl.pt

Maria Rosa Borges

mrborges@iseg.ulisboa.pt

1 ISCAL - Lisbon Accounting and Business School, Polytechnic Institute of Lisbon, Lisbon, Portugal

2 ISEG - Lisbon School of Economics and Management, Universidade de Lisboa, Lisbon, Portugal

3 UECE - Research Unit on Complexity and Economics, Lisbon, Portugal 
Keywords Emerging markets - Integrated risk modeling - Interest rate risk - Credit risk Downside risk management · Economic capital

JEL Classification $\mathrm{G} 15 \cdot \mathrm{G} 10 \cdot \mathrm{F} 39$

\section{Introduction}

The interest rate risk (IRR) and the credit risk (CR) relations are at the heart of a business model of financial institutions. Hence, IRR and CR management are among the main challenges faced by fixed-income portfolio managers and regulators.

From the point of view of prudential regulation the CR is addressed in Pillar 1 focused on minimum capital requirements ${ }^{1}$ while the IRR in the banking book (IRRBB) enters in Pillar 2 of the Basel III financial stability framework. ${ }^{2}$ Additionally the Basel III accord, see Basel Committee on Banking Supervision (2011), requires banks and other financial institutions to estimate their economic capital (ECAP) for all the material risks they face according to specificity of their businesses. This procedure is known as internal capital adequacy assessment process (ICAAP). Usually banks are forced by regulators to estimate their ECAP for CR and IRR in a segregated manner in order not to allow them to benefit from the inter-risk diversification effects. The description the de facto banking supervision landscape is based on several private communications to authors from banks, regulators, banking associations, and consulting arms of Big 4 firms.

In spite of this imposed de facto, though not really obligatory in the strict sense regulatory condition, we propose to assess CR and IRR jointly in order to calculate the respective ECAP requirements. Our study was inspired by the paper of Alessandri and Drehmann (2010). They suggest moving from the independent analyses of risks to an integrated approach. But Alessandri and Drehmann (2010) arbitrarily assume that IRR and CR amplify one another. Our paper provides the empirical evidence that it is not the case, at least for emerging market (EM) sovereign debt.

The interrelation between CR and IRR was also analyzed using non-derivative (Landschoot 2008; Boulkeroua and Stark 2013; Chen et al. 2015) and derivative (Tang and Yan 2010; Jermann and Yue 2013; Chen et al. 2013; Neal et al. 2015) instruments. The main general conclusion of these researches is that CR and IRR are related to each other and hardly separable.

Following the derivative-based studies, our paper further advances the use of the derivative instruments such as credit default swap (CDS) and interest rate swap (IRS) in approaching the interaction of the CR and IRR.

We study IRR and CR under the expansion and contraction phases of a business cycle. The interaction of these risks is assessed within the flight-to-quality time windows linked to the business cycle and also over the periods of recovery from flights-to-quality. Thus, in this manner we also contribute to the research dedicated to flight-to-quality phenomena, when capital flies from risky to risk-free assets, augmenting credit risk spreads of the former and

\footnotetext{
1 The minimum capital requirements for the credit risk (CR) are discussed in Section "Capital requirements for credit risk" of the Basel Accord, see pp. 72-189 of Regulation (EU) No 575/2013 (European Parliament 2013).

2 As for interest rate risk (IRR) no minimum capital requirements is established under the Basel Accord, see "Interest rate in the banking book" document by Basel Committee on Banking Supervision (2016) for IRR-related standards.
} 
diminishing the yields of the latter (Gubareva 2014; Fuerst et al. 2015; Gubareva and Borges 2016a).

Our contribution to the new economic thinking of IRR and CR management is twofold. First, we contribute to the empirical evidence on the mutual attenuation effects between IRR and CR resulting in inter-risk diversification benefits. Second, we provide a better theoretical understanding of the nature of inter-risk diversification benefit arising when IRR and CR are treated jointly.

We develop a derivative-based integrated framework for assessing ECAP requirements. Our approach is based on historic time series of credit default swap (CDS) spreads and interest rate swap (IRS) rates. We apply our framework to analyze risk dynamics of sovereign debt of 30 developing countries.

The application of our methodology to the EM economies is encouraged by the growing awareness of the International Monetary Fund $(2015,2016)$ related to the risks of financial instability rotating towards the developing territories. This is due to the fact that low interest rate environment in most developed countries cannot last infinitely. In its turn, banks and financial institutions all over the world face a number of systemic risk challenges and need to adapt to low growth and low interest rates, which place significant strain on their profitability and capital adequacy levels (Lin et al. 2016).

Apart from numerical simulations, we give analytical proof that due to the imperfect correlation between risks, not only in emerging markets, but in all the markets the interest rate risk is expected to attenuate credit risk and vice versa. But being also interested in providing numerical examples to show the applicability of our approach we decide to address the portfolio exposed to the sovereign debt of the EM. One of the reasons for this choice was the availability and reliability of data, apart of the already mentioned growing relevance of the developing economies in the global financial system.

The comparative analysis of the proposed here derivative-based integrated methodology with the regulatory segregated risks assessment requirements proves the robustness accuracy, and advisability of the former. Our method potentially allows for improving financial risk management practices and optimizing ECAP while complying with capital adequacy and Basel III rules. Thus, we believe that our paper provides the long-needed common basis for the discussion between financial regulators and banking industry regarding the ECAP quantification.

The rest of the paper is organized as follows. Section 2 presents the data sources. Section 3 explains the methodology. The results are presented and discussed in Sect. 4. Section 5 concludes.

\section{Data}

Our focus is on EM countries. We address those countries for which the available data are more extensive and reliable. We align our selection with the FTSE global equity index series country classification, as of September 2014, FTSE International Limited (2014). We consider three EM categories, namely, Advanced emerging, Secondary emerging, and Frontier markets.

Table 1 presents the compositions of the investigated EM portfolios, listing the countries whose contribution was considered on equal basis while modeling the respective ECAPs.

We focus on 5-year (5Y) point in the interest rate and credit spread term structures. We use CDS quotes for USD denominated instruments due to the following; first, such instrument 
Table 1 Contributing country members for the modeled EM portfolios: Advanced (AEM), Secondary (SEM) and Frontier (FEM)

\begin{tabular}{lll}
\hline AEM (Advanced EM) & SEM (Secondary EM) & FEM (Frontier EM) \\
\hline Brazil & Chile & Bahrain \\
Czech Republic & China & Cyprus \\
Hungary & Colombia & Estonia \\
Malaysia & Dubai & Lithuania \\
Mexico & Egypt & Morocco \\
Poland & Indonesia & Romania \\
South Africa & Pakistan & Serbia \\
Thailand & Peru & Slovakia \\
Turkey & Philippines & Slovenia \\
- & Russia & Tunisia \\
- & - & Vietnam \\
\hline
\end{tabular}

are much more liquid than CDS denominated in other currencies, and, second, our choice facilitates comparison of credit risks data and results across diverse geographies. As a proxy for the USD denominated risk-free interest rate we use a fixed IRS rate (Bloomberg ticker: USSW5).

\section{Methodology}

\subsection{Historical VaR approach for economic capital modeling}

Our ECAP-focused derivative-based approach to measure IRR and CR is based on a widely used technique of historical value at risk (VaR). In general terms, the VaR metrics represents the maximum loss, which is not exceeded in a given time period, called holding period, with a given probability, denominated confidence level (see, for example, Alexander 2008).

In respect to historical simulation VaR method, the main assumption is that the set of possible future scenarios is fully represented by what happened over a specific historical window. This method assumes that history will repeat itself, from a risk perspective. This methodology involves using the historical time-series of risk factor changes over a historical window. In this research, yearly changes in credit spreads and interest rates are computed on a daily basis, always over the last 5 or 7 years prior to the each date of VaR assessment. It is equivalent to saying that we use 1-year holding period, i.e., 260 banking days, along with either 5-year or 7-year long data history.

The historical set of observed scenarios is assumed to be a good representation of all possibilities that could happen in the future. Our forward-looking horizon is set to be equal to 1 year. The valuation of the portfolios is then repeated on a daily basis for each of the scenarios. This produces a distribution of portfolio values, or equivalently, a distribution of changes, profits and losses, in portfolio value relative to the value on the date of the VaR calculation. Ordering the changes in portfolio value from worst to best, the $99.9 \% \mathrm{VaR}$, for example, is computed as the loss such that $0.1 \%$ of the profits or losses are below it, and $99.9 \%$ are above it. In other words, the VaR measures the potential loss in value of a risky asset or portfolio over a defined period for a given confidence interval. 
We use the $99.9 \%$ confidence level in our VaR calculations supporting our ECAP estimates. Such practice is also consistent with the confidence level of $99.9 \%$ defined by Basel II and Basel III capital accords in the VaR-based formula for the credit risk capital requirements under the IRB approach, as per the CRR - Capital Requirements Regulation (Regulation (EU) No 575/2013 of the European Parliament, Article 153). For the regulation related discussion and implications of the regulatory choice of the confidence level, see Zimper (2014). In the absence of regulations, the confidence level for the VaR will depend on the risk attitude of the balance sheet preparer. The more risk averse is the balance sheet preparer, the higher the confidence level used in VaR calculations. That is why various confidence levels for VaR are often reported.

Additionally, when applied for the assessment of capital adequacy, VaR can be used to estimate the probability of default, i.e., the probability of insolvency. This depends on the capitalization of the bank and all the risks of its positions, which could crystallize over a chosen horizon, usually 1 year. From this point of view, the $99.9 \%$ confidence interval is somewhat equivalent to the 1-year probability of default of $0.1 \%$. While compared to the long-term default frequencies calculated by Moody's (2015) and by Standard and Poor's (2015), this figure of $0.1 \%$ permits rating the bank as an investment grade entity, which comforts regulators and solidifies the public reputation of the bank, in terms of solvency.

As mentioned above, we calculate VaR for a 1-year holding period, i.e., 260 banking days. This choice allows achieving consistency between our VaR estimates, on one hand, and, on the other hand, both, the rating agencies' 1-year default frequencies and the 1-year forward looking ICAAP statements, as traditionally the ICAAP is a forward-looking exercise with a time horizon usually equal to one calendar year.

Also, as already stated, for VaR calculations we employ two different lengths of historical data arrays, namely, of 5 and 7 years. It is important to highlight that a 5-year long array of data is a common sense minimum for $99.9 \%$ confidence levels as it provides $4 \times 260$ observations, just above the 1000 observations necessary to achieve this $99.9 \%$ confidence level. On the other hand, 7-year intervals, widely used within the financial sector, also represent a frequently met choice.

\subsection{Compounded ECAP based on a segregated assessment of IRR and credit risk}

Following the commonly used segregated approach to risk assessment in banking books, i.e., quantifying each of risks individually without considering any impact from other risks, the impact of the variation of a chosen risk parameter (RP), i.e., the historical VaR due to this RP is calculated with a confidence level of $99.9 \%$. These variations affect asset values through the discount factors employed in the net present value (NPV) calculation. The impact in value of a 5 Y maturity bond caused by 1-year move in a chosen RP, affecting yield values of this bond, ceteris paribus, could be written as

$$
\Delta \text { Value }_{260 d_{R P}}(t)=\left\{\frac{[1+\text { yield }(t)]^{5}}{\left[1+\text { yield }(t)+\Delta y \text { ield } 260 d_{R P}(t)\right]^{5}}-1\right\} \times \text { Nominal }
$$

where $\Delta y$ ield $260 d_{-} R P(t)$ represents the change in the yield caused by the analyzed RP, Nominal stands for face value or par value of the bond and $R P$ can assume values of IRR and $\mathrm{CR}$, representing correspondingly an interest rate risk and the credit risk. The above formula for $\Delta$ V alue $260 d_{-} R P(t)$ represents a result of capitalization into the future at the rate yield $(t)$ followed by discounting of the future value to the present moment at the rate yield $(t+260)$ changed due to the changes in the analyzed $R P$. 
Using the chosen 260 working days' time window we move along the time and calculate $\triangle$ Value $_{260 d_{-} R P}(t)$ for an array of consecutive dates. In this manner we receive the corresponding array of the value impacts, i.e., Array[ $\left.\Delta \operatorname{Value}_{260 d_{-} R P}(t)\right]$. Each of these two arrays, the consecutive date array or the value impact array, is a column containing the same number of fields filled with either dates or delta values, i.e., value impacts. As can be seen from Eq. (1) each delta value is determined based on the yield corresponding to a chosen date. Using the array of value impacts, constructed by consecutive computing of Eq. (1), the ECAP requirements for the RP with a confidence level of $99.9 \%$ could be written as follows:

$$
E_{C A P_{R P}}=\text { Percentile }_{99.9 \%}\left\{\text { Array }\left[-\Delta \text { Value }_{260 d_{-} R P}(t)\right]\right\}
$$

which is the absolute value or magnitude of the negative impact whose probability to occur is less than 1 out of 1000 that corresponds to the probability value of $0.1 \%$.

In our derivative based research we use IRS fixed rate quotes and CDS spread quotes to gauge variations in the interest rate and credit quality. Thus $\Delta y i e l d_{260 d_{-} I R}(t)=U S S W 5(t)-$ $U S S W(t-260)$, while $\Delta y i e l d 260 d_{-} C R(t)=C D S \_S p r e a d(t)-C D S \_S p r e a d(t-260)$, representing the change in a chosen country CDS $5 \mathrm{Y}$ spread, calculated over the holding period of 260 banking days.

According to the segregated risk assessment the total ECAP to be hold for IRR and CR is compounded as follows:

$$
E_{C A P_{\text {Compounded }}}=E_{\text {CAPR }}+\text { ECAP }_{C R}
$$

\subsection{Integrated ECAP calculation based on jointly treated IRR and credit risk}

We develop a new approach to IRR and CR assessment based on the integrated treatment of these risks. Under the proposed integrated risk approach, the impact in value of a $5 \mathrm{Y}$ maturity bond, with a face value equal to Nominal, caused by the joint dynamics of the 1-year interest rate and 1-year credit spread moves could be written as:

$$
\begin{aligned}
\Delta \text { Value }_{260 d_{I R R+C R}}(t)= & \left\{\frac{[1+\text { yield }(t)]^{5}}{\left[1+\text { yield }(t)+\Delta \text { yield }_{260 d_{I R R}}(t)+\Delta \text { yield }_{260 d_{C R}}(t)\right]^{5}}-1\right\} \\
& \times \text { Nominal }
\end{aligned}
$$

In this way, the ECAP to be held in order to withstand the joint impact of IRR and CR is:

$$
E_{\text {Integrated }}=\text { Percentile }_{99.9 \%}\left\{\text { Array }\left[-\Delta \text { Value }_{260 d_{-} I R R+C R}(t)\right]\right\}
$$

The comparison of ECAP Compounded and ECAP Integrated is capable of shedding light on interrelation between IRR and CR for any chosen geography. It is expectable that

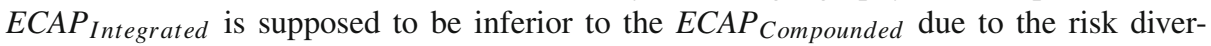
sification effect. i.e., the most value destroying 260 days moves in the interest rate and credit spread may occur and, in fact, occur over different time windows, attenuating, hence, the dynamics of their composition. It is also worth noting that, for any given holding period, the difference between $E C A P_{\text {Compounded }}$ and $E C A P_{\text {Integrated }}$ varies as a function of a length of the historical data series considered for the ECAP quantification.

A simple analogy is helpful to clarify the essence of the differences existing between $E C A P_{\text {Compounded }}$ and $E C A P_{\text {Integrated }}$. Imagine there are two traders, one trading interest rate and another credit. On most days, some diversification benefits are surely expectable. When one trader has a bad day, another one could have a good day. So, the volatility of returns as well as the severity of losses should be reduced. In the focus of our research, instead of 
these two traders, we have the two subjacent risk factors: interest rates and credit default swap spreads. And we are interested not in daily results, but in the impacts that the yearly changes in these risk parameters would produce in the value of our assets over 1 year. So when the IR year is a good one, i.e., interest rates decay, credit spreads could have also a good year of credit spread tightening or, on the contrary, a bad year of credit spread widening and vice versa.

In this context, the undiversified $E C A P_{\text {Compounded }}$ metrics tells us what might happen in a hypothetical bad-bad year. The undiversified $E C A P_{\text {Compounded }}$ is a simple summation of the ECAPs coming from the individual risk factors. The need to have such ECAP available at hand could only be crystallized over such bad-bad 1-year long period when the interest rate uptrend and credit spread widening all result together and simultaneously in the most extreme losses in each risk category. This is theoretically possible, but in reality hardly conceivable to happen. On the other hand, the metrics of the ECAP Integrated $_{\text {in }}$ is diversified by construction and takes into account the benefits of diversification, which derives from simultaneous exposure to different risk factors whose values do not rise and fall in perfect harmony. In other words, we can say that the total volatility of the two risks, CR and IRR, can be decomposed into risk-specific volatility and systematic volatility. As correlation between the risks in not perfect, the risk-specific volatility is partially diversified away resulting in lower ECAP requirements.

So when we take a 5 years $\times 260$ banking days' time-series and start to roll along the time-series our 1-year long impact gauging window with a 1-day step we continuously observe different contributions for the $E C A P_{\text {Compounded }}$ and $E C A P_{\text {Integrated }}$ arrays of the value impacts. Either the time limits of 5-year long data window, or positioning of the 1-year holding period relative to the 5-year long data window can attenuate, or make stronger, the differences of ECAP Integrated relative to ECAP Compounded $_{\text {B }}$ But, in fact, the attenuation of the $E C A P_{\text {Integrated }}$ metrics relative to $E C A P_{\text {Compounded }}$ value derives not so much from the windows themselves, but from the volatility and trends of spread curves and yield curves, subjacent to these windows, which transcribe macroeconomic conditions such as gross domestic product growth rates, flat or inverted interest rate and credit spread term structures, excessive volatility of credit default swaps, etc.

At this point we provide analytical proof of the inequality: ECAP Integrated $<E C A P_{\text {Compounded }}$. As our ECAP USD-denominated figures are calculated by means of the $\mathrm{VaR}$ technique, the $E C A P_{\text {Integrated }}$ metrics could be expressed through the standard formula operating with risk-specific segregated ECAPs and correlation between risks:

$$
E C A P_{\text {Integrated }}=\sqrt{\left(E C A P_{C R}\right)^{2}+\left(E C A P_{I R R}\right)^{2}+2 \rho_{C R, I R R} E C A P_{C R} E C A P_{I R R}}
$$

where $\rho_{C R, I R R}$ stands for the correlation coefficient between CR and IRR, and $E C A P_{C R}$ and $E C A P_{I R R}$ are segregated risk-specific ECAP requirements for, respectively, credit risk and interest rate risk considered as stand-alone. So, it is shown analytically that $E C A P_{\text {Integrated }}$ is inferior to $E C A P_{\text {Compounded }}$, which equals a sum of $E C A P_{C R}$ and $E C A P_{I R R}$ as these risks are not perfectly correlated and hence the correlation parameter is less than 1 . Only under unrealistic circumstances, when $\mathrm{CR}$ and IRR would be perfectly correlated, the ECAP Integrated could be equal to the ECAP Compounded .

It means that inequality $E C A P_{\text {Integrated }}<E C A P_{\text {Compounded }}$ is true for all markets and not only for EM. But we decide to numerically model ECAPs for the portfolios exposed to the sovereign debt of the EM. The outcomes of our integrated approach and its comparison to the segregated approach will be discussed in more detail while addressing our results. 


\subsection{ECAP-wise elasticity of IRR and CR}

To study cross-elasticity of IRR and CR impacts, we analyze a problem of minimizing the ECAP by diminishing a joint sensitivity of a bond and its tailor-optimized hedge by IRS contract towards the integrated impacts of the aforementioned risks. For such hedge pair consisting of a bond and its hedging instrument we construct a hypothetical impact in value due to 1-year moves in interest rate and credit spread using an expression:

$$
\begin{aligned}
& \Delta \text { Value 260_Hedge_Pair }(t)=\Delta \text { Value260_IR }(t) \times \text { Hedge Coefficient } \\
& +\triangle \text { Value }_{260 \_I R R+C R}(t)
\end{aligned}
$$

Then the ECAP for the chosen hedge pair is computed:

$$
E C A P_{\text {Hedge_Pair }}=\text { Percentile } 99.9 \%\left\{\text { Array }\left[-\Delta \text { Value } 260 d_{-} \text {Hedge_Pair }_{-}(t)\right]\right\}
$$

Defined in this manner ECAP $P_{\text {Hedge_Pair }}$ depends on Hedge_Coefficient. Thus, varying Hedge_Coefficient we solve the ECAP minimization problem:

$$
\begin{aligned}
& \text { ECAP Minimum_Hedge_Pair }= \\
& \text { MINIMUM Hedge_Coefficient }\{\text { ECAP Hedge_Pair }[\text { Hedge_Coefficient }]\}
\end{aligned}
$$

The value of the hedge coefficient, which corresponds to the minimum possible ECAP, defines a possible downside risk hedge strategy from the capital optimization point of view.

In other words, the value of the hedge coefficient characterizes the cross-elasticity of IRR and CR as seen from the point of view of ECAP optimization. Thus, if the Hedge_Coefficient is equal to 0 , it means that from capital minimization perspective no hedge is needed, as joint dynamics of the interest rate and credit spread already results in the minimum possible capital requirements. It signifies that in this case the cross-elasticity of IRR and CR equals -1 , as the subjacent changes in interest rate cancel out negative impacts from credit-spread dynamics with maximum efficiency. If Hedge_Coefficient is equal to a positive value $r$, it means that in order to diminish exposure to downside risk we may need to augment exposure to the IRR by contracting pay-float receive-fixed IRS with notional, equal to Nominal $\times r$. It signifies that in this case the cross-elasticity of IRR and CR equals $-1-r$, i.e., below -1 , as additional exposure to the IRR is needed for cancelling out negative impacts from credit-spread moves the most efficiently possible. On the other hand, if Hedge_Coefficient is equal to a negative value $r$, it means that in order to diminish exposure to downside risk we may need to diminish exposure to the IRR by contracting pay-fixed receive-float IRS with notional, equal to Nominal $\times(-r)$. It signifies that in this case the cross-elasticity of IRR and CR equals $-1-r$, i.e., above -1 , as reducing the excess exposure to the IRR is benefic for the most efficient cancelling out negative impacts from credit-spread dynamics. At the singularity point $r=-1$, the cross-elasticity becomes 0 , meaning that the credit spread dynamics is unrelated to the dynamics of the interest rate, as any non-zero exposure to the IRR worsens the overall ECAP figure.

Apart of cross-elasticity of IRR and CR, many other aspects of diverse nature are needed to be taken into account while evaluating a necessity of IRS-based hedging contracts, such as regulatory limits of the maximum possible impacts of parallel shifts of interest rate curves, accounting efficiency of IRR hedge, and overall profitability of the portfolio, among others. Still an issue of targeting ECAP minimization through downside risk hedging, addressed herein, seems to be undeservedly overlooked by both, academics and practitioners. At least, an ECAP-wise elasticity of IRR and CR should be taken into consideration while optimizing downside risk hedge strategies implementation and ECAP allocation. 
From a practical standpoint, each time one decides to define an optimal ECAP-wise hedge strategy, i.e., to dimension a hedging instrument in a chosen hedge pair in such a way that it would work best in hedging one's exposure, the ECAP minimization problem as per Eq. (9) must be solved numerically using the chosen length and chosen time limits of the historical data series. Table 6 in the Sect. 4.3 provides several examples of hedge pairs dimensioning.

Obviously, a subjective judgment always exists while determining an optimal hedge strategy, as past performance does not guarantee future results. So, it is important to thoroughly choose such past history, which could be sufficiently representative of what can happen in future market conditions.

Surely, the choice of a length of historical data samples as well as holding periods and levels of confidence will make ECAP fluctuate. But certain meaningful conclusions can be derived from comparison of ECAP requirements for the unhedged positions to ECAP requirements for the pairs including the corresponding bonds and the optimally dimensioned hedge by IRS instruments. Numerical examples of such comparison, i.e., what capital could be potentially disposable from economic point of view, are given further in the text in Sect. 4.2, Tables 4 and 5 .

\subsection{Unexpected loss quantified by internal ratings-based (IRB) foundation approach}

The outcomes of the derivative-based model for economic capital are compared to results of capital requirements quantification based on comparison of its results country by country with outcomes of the regulatory Basel II/III formula for economic capital under the $i$ nternal $r$ atings based (IRB) Foundation approach as defined by CRR - Capital Requirements Regulation (Regulation (EU) No 575/2013 of the European Parliament, Article 153). Under this approach, using the risk-weighted factor of $8 \%$, capital requirements for exposures to corporates, institutions, and central governments shall be calculated according to the following formulae:

$$
\begin{aligned}
& E C A P= \\
& \text { exposure value } \times\left[L G D \times N\left(\frac{1}{\sqrt{1-R}} \times G(P D)+\sqrt{\frac{R}{1-R}} \times G(0.999)\right)-L G D \times P D\right] \\
& \times \frac{1+(M-2.5) b}{1-1.5 b} \times 1.06
\end{aligned}
$$

where $N(x)$ is the cumulative distribution function for a standard normal random variable (i.e., the probability that a normal random variable with mean zero and variance of one is less than or equal to $\mathrm{x}$ ); $G(Z)$ denotes the inverse cumulative distribution function for a standard normal random variable (i.e., the value $x$ such that $N(x)=z$ ); $R$ denotes the coefficient of correlation, is defined as:

$$
R=0.12 \times \frac{1-e^{-50 \times P D}}{1-e^{-50}}+0.24 \times\left(1-\frac{1-e^{-50 \times P D}}{1-e^{-50}}\right)
$$

and $\mathrm{M}$ represents the maturity term while $b$ stands for the maturity adjustment factor: $b=$ $(0.11852-0.05478 \times \ln (P D))^{2}$.

We use a regulatory value of $45 \%$ for the senior debt LGD (loss given default) parameter. To assess $P D$ (probability of default) parameter we use a Basel rating (second best rating) based on two rating agencies Moody's and Standard \& Poor's. Then, according to the country Basel rating, the second best one, we attribute to the country a $P D$ equal to the average of 
the long term default frequency calculated by Moody's (2015) over the years 1983-2014 and of the long term default frequency calculated by Standard and Poor's (2015) over the years 1981-2014.

It can be demonstrated that the results of derivative-based integrated approach to risk assessment are consistent with the described above IRB Foundation approach. Still being more issuer specific our derivative-based approach to integrated treatment of IRR and CR seems to be more comprehensive and hence allowing for better optimizing bank economic capital.

\section{Results and discussion}

\subsection{ECAP for EM portfolios: segregated versus integrated approach to risk assessment}

We compare compounded ECAP requirements with the ECAP requirements quantified following the proposed herein integrated approach to risk assessment, and present potentially disposable fund as a difference between these two estimates in the two tables below for 5Y-long and 7Y-long VaR series. We perform this analysis on the equally weighted portfolio basis. The figures in Tables 2 and 3 are averages of the country specific metrics under the three considered emerging market categories, namely AEM, SEM, and FEM.

Analyzing ECAP requirements for the Advanced, Secondary, and Frontier equally weighted portfolios some common patterns could be observed. First, as could be seen for both, $5 \mathrm{Y}$ and $7 \mathrm{Y}$ lengths of VaR series, the ECAP under the integrated approach is considerably lower than the compounded ECAP following the segregated approach. The former on

Table 2 ECAPs for EM portfolios as of Dec-2014 with 5Y-long VaR history

\begin{tabular}{lllrr}
\hline $\begin{array}{l}\text { 5Y-long VaR history } \\
\text { confidence interval }\end{array}$ & & \multicolumn{2}{l}{ Portfolios } & \\
\cline { 3 - 5 } & & AEM & SEM & FEM \\
\hline CR ECAP (\%) & (A) & 6.33 & 5.82 & 11.00 \\
IRR ECAP (\%) & $(\mathrm{B})$ & 5.28 & 5.22 & 5.16 \\
Compounded ECAP (\%) & (C = A + B) & 11.65 & 11.04 & 16.16 \\
Integrated ECAP (\%) & (D) & 6.23 & 6.40 & 10.02 \\
Disposable ECAP (\%) & (E $=\mathrm{C}-\mathrm{D})$ & 5.42 & 4.64 & 6.14 \\
\hline
\end{tabular}

Table 3 ECAPs for EM portfolios as of Dec-2014 with 7Y-long VaR history

\begin{tabular}{llrrr}
\hline 7Y-long VaR history $\begin{array}{l}\text { Portfolios } \\
\text { confidence interval }\end{array}$ & & AEM & SEM & FEM \\
\cline { 3 - 5 } & & 13.01 & 14.83 & 17.09 \\
\hline CR ECAP $(\%)$ & $(\mathrm{A})$ & 5.27 & 5.21 & 5.20 \\
IRR ECAP (\%) & $(\mathrm{B})$ & 18.28 & 20.04 & 22.29 \\
Compounded ECAP $(\%)$ & $(\mathrm{C}=\mathrm{A}+\mathrm{B})$ & 8.93 & 10.98 & 13.52 \\
Integrated ECAP $(\%)$ & $(\mathrm{D})$ & 9.35 & 9.06 & 8.77 \\
Disposable ECAP $(\%)$ & $(\mathrm{E}=\mathrm{C}-\mathrm{D})$ & &
\end{tabular}


average is roughly equal to 51,56, and $61 \%$ of the latter for Advanced EM, Secondary EM, and Frontier markets, respectively.

Second, comparing 5Y- and 7Y-long VaR series one could conclude that the less Advanced are markets, the greater are non-diversifiable CR components. It also could be interpreted as that the exposures to the debt of the less Advanced markets are less sensible to the IRR.

Third, for 7Y-long data series, the ECAP requirements under both integrated and segregated approaches are higher than for the respective 5Y-long VaR sample that does not capture the entire history of the crisis development.

Fourth, the common pattern we also observe is that the ECAP requirements under the integrated approach are consistently lower than those defined through the segregated approach to ECAP requirements solely for CR. This fact clearly indicates that for 7Y-long VaR series considered herein, the interest rate downtrend dynamics mitigate the credit spread widening. The following subsections address this observation in more detail first, by considering different phases of business cycle and, second, by developing the downside risk hedge strategy based on ECAP-wise cross-elasticity of IRR and CR.

\subsection{ECAP for expansion and contraction phases of business cycle}

Interrelations of IRR and CR differ between expansion and contraction phases of business cycle. Gubareva (2014) observes that during the periods of capital migration from risky to safe assets, defined as flight-to-quality, the CR spreads of the formers increases while the yields of the latter evaporate. Such CR spreads and interest rates dynamics took place during the recent financial crisis, when interest rates dropped and simultaneously the average creditworthiness of debt issuers, being banks, corporates or sovereigns, deteriorated too. Gubareva (2014) and Gubareva and Borges (2016a) argue that it is not an exceptional case but rather common and expectable circumstances, as crashes and recessions usually always coincide with downward tendency in interest rates dynamics.

To address this issue further on, in Tables 4 and 5 we present our results on potentially disposable ECAP for the two time windows, namely, pre- and post-crisis phases of the cycle. For these analyses a selected set of sixteen developing countries was employed, as only for these countries we had an access to the necessary length of historical CDS spread quotes. For each country, and for each 5-year long time window covering the employed historical data, we numerically solve the ECAP minimization problem (see Eq. 9). As commented in Sect. 3.4, an optimal ECAP-wise dimensioning of hedging instrument, and hence potentially disposable ECAP depends upon the risk factors histories covered by the chosen length of time windows used to gauge ECAP requirements.

Let us consider the concrete example of Brazil. The potentially disposable ECAP evaluated over Dec 2003-Dec 2008 period is found to represent $11.08 \%$, while the same figure evaluated over the Dec 2008-Dec 2013 period equals to 1.40\%. Looking forward and trying to define the optimal ECAP-wise hedge for the future, one needs to make a judgment deciding what array of available historical data suits better for describing the future market conditions from the risk point of view: Dec 2003-Dec 2008; Dec 2008-Dec 2013; Dec 2007-Dec 2014, or any other? The only undoubted thing is that a certain amount of ECAP will always be considered as potentially disposable under each and any adopted assumption. Most likely, no one will opt for selecting the "extreme" options presented in Tables 4 and 5, pre-crisis and post-crisis conjuncture, respectively. Hence, it is more likely the potentially disposable future ECAP will be inside the interval $1.40-11.08 \%$. We will continue this discussion further on, while analyzing Table 6 . 
Table 4 ECAPs estimated with 5Y VaR for December 2008

\begin{tabular}{llllll}
\hline Country/portfolio & CR ECAP $(\%)$ & $\begin{array}{l}\text { IRR ECAP }(\%) \\
\text { Compounded } \\
\text { ECAP }(\%) \\
(\mathrm{C}=\mathrm{A}+\mathrm{B})\end{array}$ & $\begin{array}{l}\text { Integrated } \\
\text { ECAP }(\%)\end{array}$ & $\begin{array}{l}\text { Disposable } \\
\text { ECAP }(\%)\end{array}$ \\
\hline Brazil (AEM) & 20.38 & 7.42 & 27.80 & 16.72 & 11.08 \\
Chile (SEM) & 12.99 & 7.80 & 20.79 & 8.80 & 11.99 \\
China (SEM) & 11.20 & 7.80 & 19.00 & 7.54 & 11.46 \\
Colombia (SEM) & 19.36 & 7.54 & 26.90 & 15.65 & 11.25 \\
Hungary (AEM) & 22.86 & 7.81 & 30.67 & 19.31 & 11.36 \\
Malaysia (AEM) & 18.34 & 7.79 & 26.13 & 14.47 & 11.66 \\
Mexico (AEM) & 21.93 & 7.75 & 29.68 & 18.33 & 11.35 \\
Peru (SEM) & 19.85 & 7.55 & 27.40 & 16.06 & 11.34 \\
Philippines (SEM) & 25.93 & 7.46 & 33.39 & 22.59 & 10.80 \\
Poland (AEM) & 11.51 & 7.80 & 19.31 & 8.20 & 11.11 \\
Romania (FEM) & 25.80 & 7.70 & 33.50 & 20.54 & 12.96 \\
Russia (SEM) & 36.69 & 7.69 & 44.38 & 33.92 & 10.46 \\
Slovakia (FEM) & 9.79 & 7.81 & 17.60 & 7.45 & 10.15 \\
South Africa (AEM) & 23.73 & 7.75 & 31.48 & 20.17 & 11.31 \\
Thailand (AEM) & 17.57 & 7.80 & 25.37 & 13.75 & 11.62 \\
Turkey (AEM) & 24.99 & 7.56 & 32.55 & 21.62 & 10.93 \\
Average & 19.85 & 7.69 & 27.54 & 16.08 & 11.46 \\
\hline
\end{tabular}

Table 5 ECAPs estimated with 5Y VaR for December 2013

\begin{tabular}{lcllll}
\hline Country/portfolio & CR ECAP $(\%)$ & $\begin{array}{l}\text { IRR ECAP }(\%) \\
\text { Compounded } \\
\text { ECAP }(\%) \\
(\mathrm{C}=\mathrm{A}+\mathrm{B})\end{array}$ & $\begin{array}{l}\text { Integrated } \\
\text { ECAP }(\%)\end{array}$ & $\begin{array}{l}\text { Disposable } \\
\text { ECAP }(\%)\end{array}$ \\
\hline Brazil (AEM) & 4.95 & 5.29 & 10.24 & 8.84 & 1.40 \\
Chile (SEM) & 4.08 & 5.31 & 9.39 & 5.76 & 3.63 \\
China (SEM) & 6.00 & 5.31 & 11.31 & 6.35 & 4.96 \\
Colombia (SEM) & 4.67 & 5.30 & 9.97 & 6.62 & 3.35 \\
Hungary (AEM) & 16.17 & 5.16 & 21.33 & 12.86 & 8.47 \\
Malaysia (AEM) & 5.91 & 5.30 & 11.21 & 7.08 & 4.13 \\
Mexico (AEM) & 4.57 & 5.30 & 9.87 & 6.45 & 3.42 \\
Peru (SEM) & 4.86 & 5.30 & 10.16 & 6.89 & 3.27 \\
Philippines (SEM) & 5.88 & 5.29 & 11.17 & 5.14 & 6.03 \\
Poland (AEM) & 8.53 & 5.29 & 13.82 & 7.31 & 6.51 \\
Romania (FEM) & 11.08 & 5.18 & 16.26 & 7.52 & 8.74 \\
Russia (SEM) & 7.56 & 5.28 & 12.84 & 7.60 & 5.24 \\
Slovakia (FEM) & 11.79 & 5.28 & 17.07 & 9.21 & 7.86 \\
South Africa (AEM) & 5.25 & 5.29 & 10.54 & 9.60 & 0.94 \\
Thailand (AEM) & 6.60 & 5.29 & 11.89 & 6.30 & 5.59 \\
Turkey (AEM) & 8.94 & 5.27 & 14.21 & 9.64 & 4.57 \\
Average & 6.26 & 5.28 & 11.54 & 5.66 & 5.88 \\
\hline
\end{tabular}




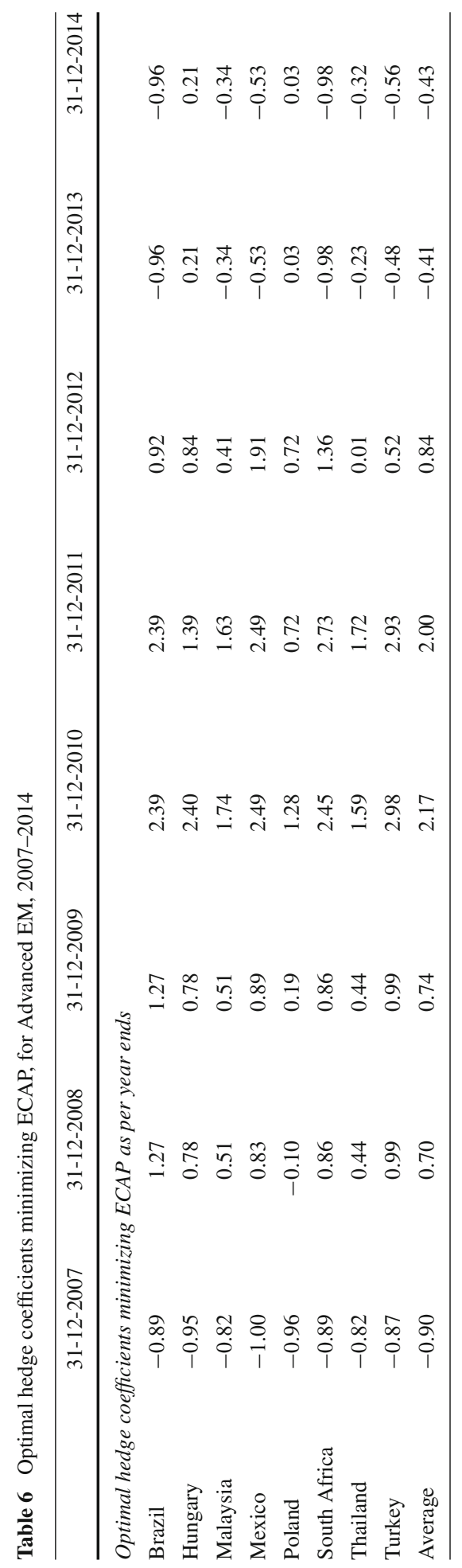


Comparing Tables 5 and 6, the following statements could be made. First, we observe that diversification benefits of the integrated treatment of CR and IRR are more significant for the 2004-2008 period. Second, taking into consideration the absolute values of the CR and IRR requirements we observe that the proposed herein derivative-based integrated approach accounts correctly for the higher riskiness of the 2004-2008 period. Third, one could infer that if the exposure to the IRR in the pre-crisis/crisis period would be bigger, the inter-risk diversification benefits could be also greater, reducing in this manner the ECAP requirements under the integrated approach. In the next section, we discuss in more detail the role of interaction between the IRR and CR for the ECAP calculation from the perspective of the economic capital-wise elasticity of the IRR and CR.

\subsection{Economic capital-wise cross-elasticity of IRR and CR: selected EM countries}

To further study the relation between the interest rate and credit risk, we present the results of our study on the cross-elasticity of the IRR and CR impacts analyzed through the prism of ECAP quantification. For the hedge pair consisting of a bond and its hedging IRS contract we minimize hypothetical ECAP requirements quantified with $99.9 \%$ confidence level. Our calculations are performed for the year-ends of the eight consecutive years, since 2007 until 2014, based on 5Y long data history employed in our VaR calculations.

In Table 6 below for the Advanced EM countries we present the values of optimal downside hedge coefficient minimizing ECAP of the aforementioned hedge pair, consisting of a bond and a hedging it IRS.

Once again, for each country and for each 5-year long time window covering the employed historical data we numerically solve the ECAP minimization problem, see Eq. 9. We see that the optimal ECAP-wise hedge coefficient changes from year to year, because the 5-year long data history used in ECAP calculations changes. Let us continue to analyze Brazil. From a practical standpoint the optimal ECAP-wise hedge during the years 2003-2007 would be contracting pay-fixed receive-float IRS with its notional equal to $89 \%$ of bond nominal value. But going 1 year forward the situation is changed. The optimal ECAP-wise hedge during the years 2004-2008 would be contracting pay-float receive-fixed IRS with its notional equal to $127 \%$ of bond nominal value. It corresponds to $11.08 \%$ of potentially disposable ECAP, as shown in Table 4.

Continuing our discussion of optimal hedge coefficient and disposable ECAP, in Table 6 we observe that the optimal ECAP-wise hedge during the years 2008-2013 would be contracting pay-fixed receive-float IRS with its notional equal to $96 \%$ of bond nominal value. It corresponds to $1.40 \%$ of potentially disposable ECAP, as shown in Table 5. Averaging the optimal hedge coefficients shown in the first line of the Table 6, we can have an average perception of what would be an appropriate "medium" hedge along all the considered years. So, as the mean value of the Brazil optimal hedge coefficient is 0.68 , the optimal ECAP-wise hedge during the years 2003-2014 would be contracting pay-float receive-fixed IRS with its notional equal to $68 \%$ of bond nominal value. This is consistent with the result for aggregate Advanced EM portfolio of $0.60 \%$, see Fig. 1 and the following discussion. Now let us continue our discussion of Table 6 on the aggregate portfolio level.

We observe that the ECAP-minimizing hedge coefficient is a function of the considered time windows. For the pre-crisis period 2003-2007 for all the considered countries the ECAP minimizing hedge coefficient on average is closed to -0.9 . It means that in order to diminish exposure to downside risk during the economy expansion phase of business cycle, we may need to diminish exposure to the IRR by contracting pay-fixed receive-float IRS with notional roughly equal to 0.9 times Nominal of an analyzed Advanced EM bond. 


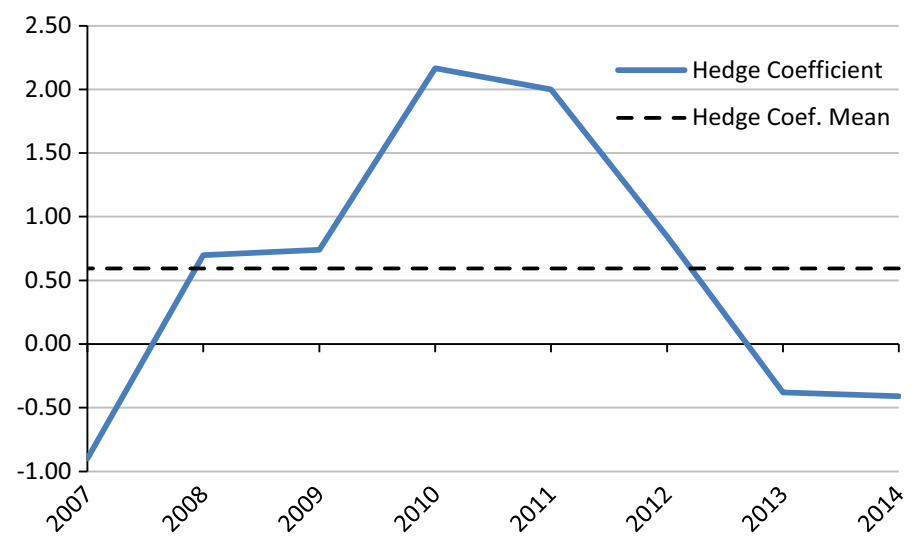

Fig. 1 ECAP-minimizing downside hedge coefficient for the AEM portfolio, 2007-2014

As the 5Y-long VaR data history starts to overlap the apogee of the global financial crisis which took place in 2008, since the 2004-2008 time window to the 2008-2012 one, we see at the aggregate portfolio level that the ECAP-minimizing hedge coefficients begin to assume positive values, meaning that augmenting exposure to IRR was capable of canceling out the negative impacts of the widening credit spreads. Under these circumstances, in order to diminish exposure to downside risk we may need to augment exposure to the IRR by contracting pay-float receive-fixed IRS with notional, equal to bond's Nominal times hedge coefficient.

For the post-crisis years of economic recovery the majority of the ECAP-minimizing hedge coefficients newly assume negative values, though on average they represent roughly a half of the pre-crisis figures due to rather modest economic growth, see two columns on the right-hand side of Table 6. It means that in order to diminish exposure to downside risk during the recovery from the crisis, we may need to diminish exposure to the IRR.

In general, the findings described in the two last paragraphs serve as a convincing indication of the binary behavior of the IR sensitivity of the sovereign debt exposures. In our more recent work, Gubareva and Borges (2016b), following a different, non-derivative, bond yield-based approach we demonstrate the binary IR sensitivity of EM corporate bonds. Thus, further research on the behavior of the IR sensitivity of sovereign debt is highly desirable.

In particular, along the post-crisis period a few hedge coefficients for certain countries, e.g., Hungary and Poland, exhibit values closed to zero, signifying that IRR and CR for these exposures present almost perfect negative correlation, probably due to the relatively low embedded leverage, and proving unnecessary downside risk hedge by means of USD denominated IRS contracts.

In Fig. 1 we plot the time dependence of the ECAP-minimizing downside hedge coefficient averaged over the aforementioned hedge pairs for the considered Advanced EM countries portfolio (see also the bottom line of Table 6).

Figure 1 indicates that the ECAP-minimizing downside hedge coefficient on average exhibits positive values for the year-ends since 2008 until 2012, i.e., when 5 Y long VaR series include the crisis apogee year of 2008. Thus, during this period the augmenting exposure to IRR would be benefic in the sense of the ECAP optimization. The stronger affirmation is also correct: over all the considered data history, from 2003 until 2014 the mean value of the hedge coefficient is about 0.6 . Thus, constantly maintaining the exposure to the IRR augmented in $60 \%$ would make us better off in terms of capital allocation. 
Additionally, as could be seen from the Fig. 1, the portfolio level ECAP-minimizing downside hedge coefficient reaches its maximum of 2.17 in December 2010. It means that to minimize the portfolio ECAP, based on the VaR history of 2006-2010, i.e., to diminish the exposure to downside risk, we ought to augment exposure to the IRR by contracting pay-float receive-fixed IRS with notional, equal to Nominal $\times 2.17$. It signifies that the cross-elasticity of IRR and CR over this period was about -3.17 , i.e., the benefic influence of the IRR component in the bond yield should be augmented 3 times by means of contracting the dimensioned above pay-float receive-fixed IRS with roughly doubled notional in respect to the portfolio nominal.

In Table 5 we present ECAP-wise cross-elasticity between IRR and CR derived from the values of optimal downside hedge coefficient minimizing ECAP of the Advanced EM countries.

The fact that one sees the negative sign in front of the algorithms in the Table 7 intends to stress that for the analyzed time frames and countries, the augmenting of the IRR exposures diminishes downside risk for the respective hedge pairs consisting of a bond and a hedging it IRS. It is also worth noting that the downside risk hedging could be performed either on individual level, or on the aggregated portfolio level.

In Table 8 we compare the ECAP requirements for non-hedged bonds and achievable minima of ECAP requirements under the optimal downside risk hedge, potentially feasible by means of the optimal hedge with IRS contracts dimensioned according to the coefficients, exposed in Table 6.

This table clearly evidences that downside risk hedging makes possible the diminishing of the ECAP requirements for all the considered herein reference dates and for all the selected developing geographies. It is also worth noting that ECAP requirements at individual country level as well as at the AEM portfolio level remain unchanged, maintaining the value of 16.86, between December 2009 and December 2011. The explanation of this observed phenomenon is that the major negative impacts calculated with 1-year holding period for the three subjacent 5Y VaR series (2005-2009, 2006-2010, and 2007-2011) are the same and correspond to the apogee of the financial crisis. On the other hand, the sensitivity of the individual positions and of the entire portfolio to the interest rate changes along the time scale. This results in the changing values of the corresponding ECAP minima under the optimal hedge conditions.

In Fig. 2 we plot the minimal stock of ECAP for the bond portfolio of the selected above Advanced EM countries hedged by optimized IRS contracts against the downside risk. We also indicate the level corresponding to the mean values of the ECAP minimum, which we find to be equal to $7.6 \%$ of the portfolio nominal.

Potentially disposable funds under the above-mentioned optimal downside hedge strategies are presented in Table 9.

The mean value of the potentially attainable gain in the ECAP under downside risk hedging for the eight considered here year-ends is equal to $5.2 \%$ of the portfolio nominal. That seems to be quite an impressive reserve for the risk taking capacity, which could unleash lending and investment capacity of banks and other financial institutions.

In Fig. 3 we plot the potentially disposable, or potentially freed, stock of ECAP for the bond portfolio of the selected above Advanced EM countries hedged by optimized IRS contracts against the downside risk. We also indicate the level corresponding to the mean values of the disposable ECAP, which we find to be equal to $5.2 \%$ of the portfolio nominal.

Of course many other aspects, such as profit targets and regulatory limits of exposure to IRR need to be taken into account while evaluating a necessity of IRS-based hedging strategy. 


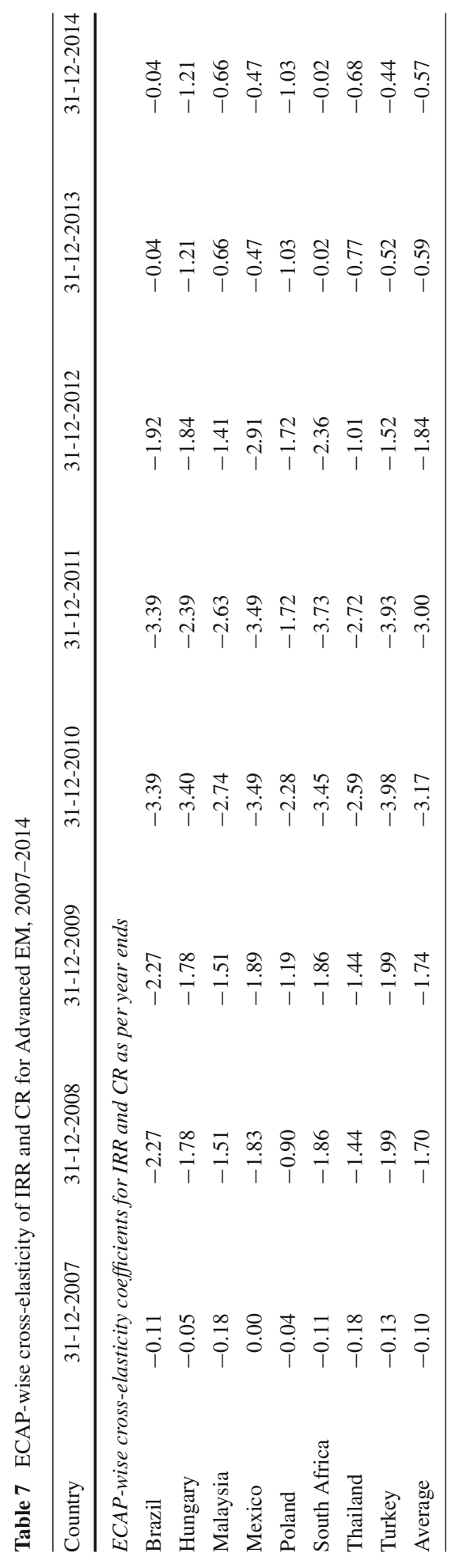




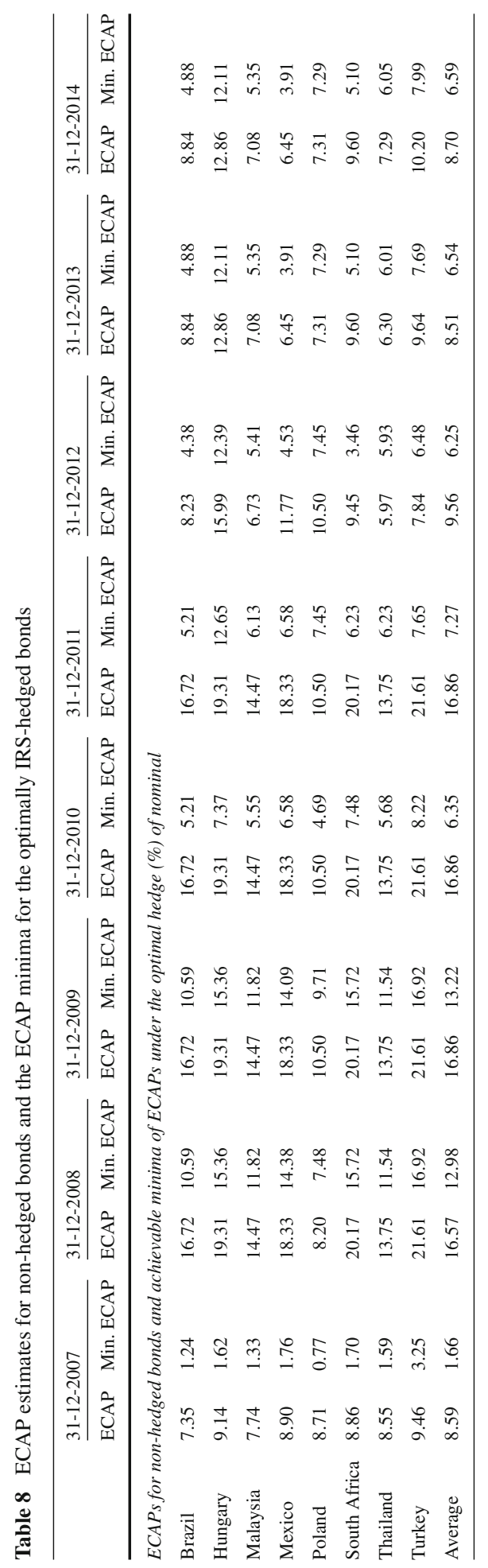




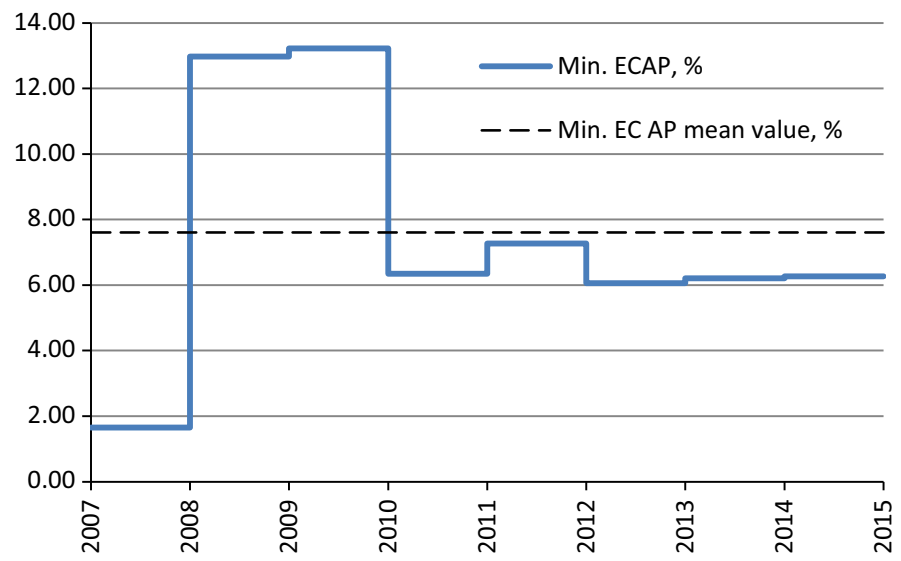

Fig. 2 Minimum ECAP requirements achievable for the Advanced EM bond portfolio

\subsection{Derivative-based integrated approach benchmarked against the Basel III regulation}

On a country-by-country basis, the outcomes of the derivative-based model for ECAP are compared to the results of capital requirements quantification based on the regulatory Basel II/III formula for economic capital under the internal ratings based (IRB) Foundation approach. Below, in Tables 10, 11, 12 and 13, we present our results both, for the CDSbased CR historic methodology and the CR regulatory approach for the Advanced EM, the Secondary EM, and the Frontier markets respectively.

Comparing the last two columns of the above Tables 10, 11, and 12 one could observe that the capital requirements for the CR computed according to the regulatory formula are well below the CDS-based estimates for the ECAP regarding CR. The only exceptions are Pakistan and Serbia whose ratings seem not to reflect recent improvements in their creditworthiness. This result is quite expectable as we used the long run default frequencies as proxies for probabilities of default. Under the regulatory approach, it is an admissible procedure both by market participants and regulators, which became a well-spread market practice especially under the through-the-cycle approach.

Going one step further at this point we calculate the total compounded ECAP represented by a sum of the regulatory Pillar 1 CR requirements and the Pillar 2 IRS-based historic VaR IRR requirements and compare this compounded ECAP to the ECAP estimated following the proposed herein integrated derivative-based approach to risk assessment.

It is worth noting that the developed herein integrated risk assessment builds upon a standard historic VaR technique, commonly employed for evaluating impacts of segregate risks considered as stand-alone. But the presented innovative modeling methodology allowed us to apply the well-known historic VaR technique to simultaneously assess impacts produced by joint dynamics of several risks. Herein we consider just two of them, interest rate risk and credit risk. So, diverting from mainstream segregated VaR approaches, we apply the historic VaR technique to the time-series, which were generated taking into account the aggregate value impacts coming simultaneously from different risk parameters, namely interest rates and credit spreads.

In Tables 13, 14, and 15 we explicitly show the delta between the results of these two approaches. For instance, for column A data we may say that the segregate approach subsumes 


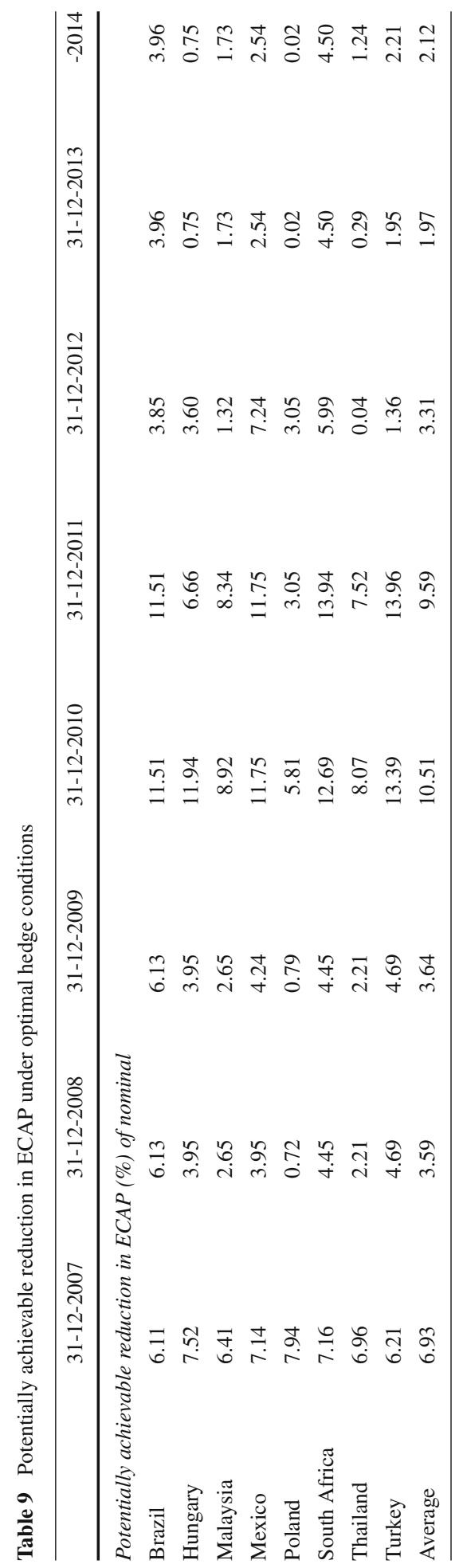




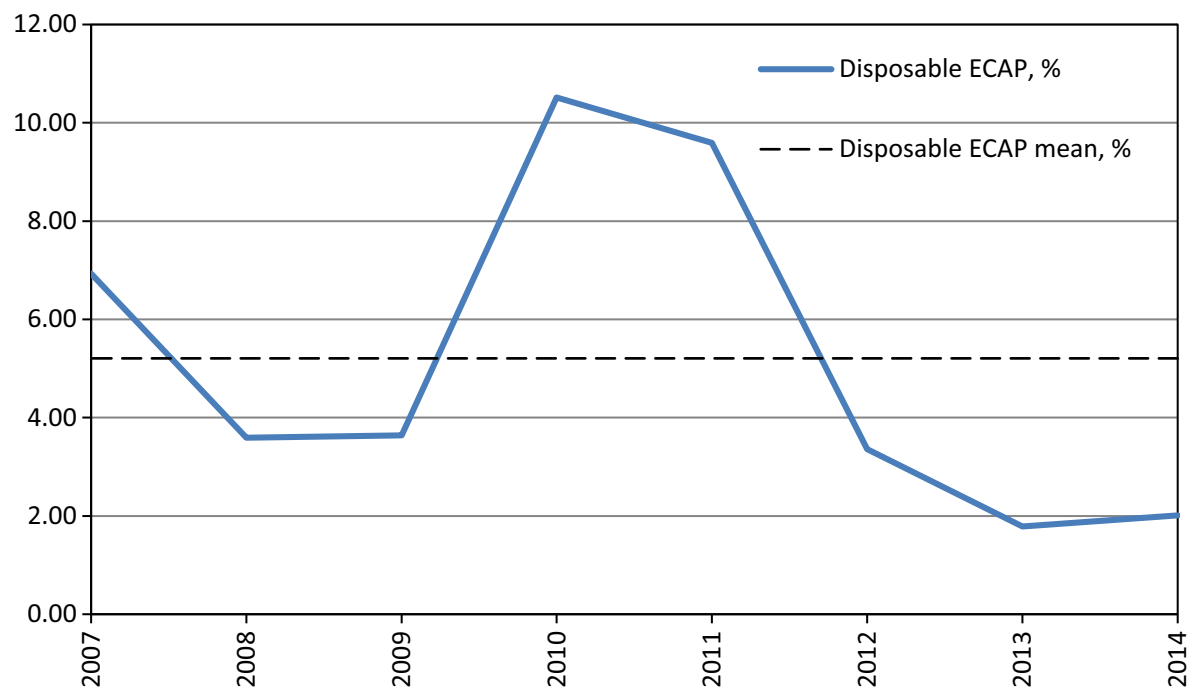

Fig. 3 Potentially disposable stock of ECAP for the bond portfolio of the Advanced EM countries hedged against the downside risk by optimized IRS contracts

the information content of the already existed mainstream historic VaR approach, while for the column $\mathrm{D}$ it is valid to state that the newly developed modeling permits to draw new relationship between the considered risk parameters and the economic capital requirements allowing to withstand eventual adverse crystallizations of interest rate and credit risk.

Hence, it is empirically demonstrated that the results of the proposed derivative-based integrated approach to the risk assessment are consistent with the Basel III IRB Foundation approach. The average delta, excluding turmoil subjected Cyprus, is about $1.39 \%$ certifying that proposed herein approach is competitive in the sense that its outcomes present a lesser capital charge while compared to the outcomes of the regulatory formula under the segregated risk treatment. Additionally, being more issuer specific our derivative-based approach to integrated treatment of IRR and CR seems to be more comprehensive and, thus, allowing for better optimizing of economic capital to be held by a bank in order to withstand the joint impact of IRR and country specific CR.

\subsection{ECAP for a portfolio of selected EM countries}

To study how the ECAP calculated following the proposed herein integrated derivative-based approach behaves along the time we select eight Advanced EM countries, namely Brazil, Hungary, Malaysia, Mexico, Poland, South Africa, Thailand, and Turkey. We choose these countries as they belong to Advanced EM and as only for these Advanced EM countries we managed to have an access to the necessary length of historical CDS spread quotes. We perform our modeling for all the years for which we have a regulatory minimum of $5 \mathrm{Y}$ history for VaR analysis. Figure 4 depicts the dynamics of the ECAP following both, the integrated and the segregated approach to the risk assessment. These calculations are made directly on the eight-countries portfolio level and thus benefit from credit risk diversification.

As could be seen from Fig. 4, the integrated approach to risk assessment allows for optimizing the ECAP. We would like to highlight that under our approach all the results could be drilled down in order to understand which components are responsible for major impacts. 


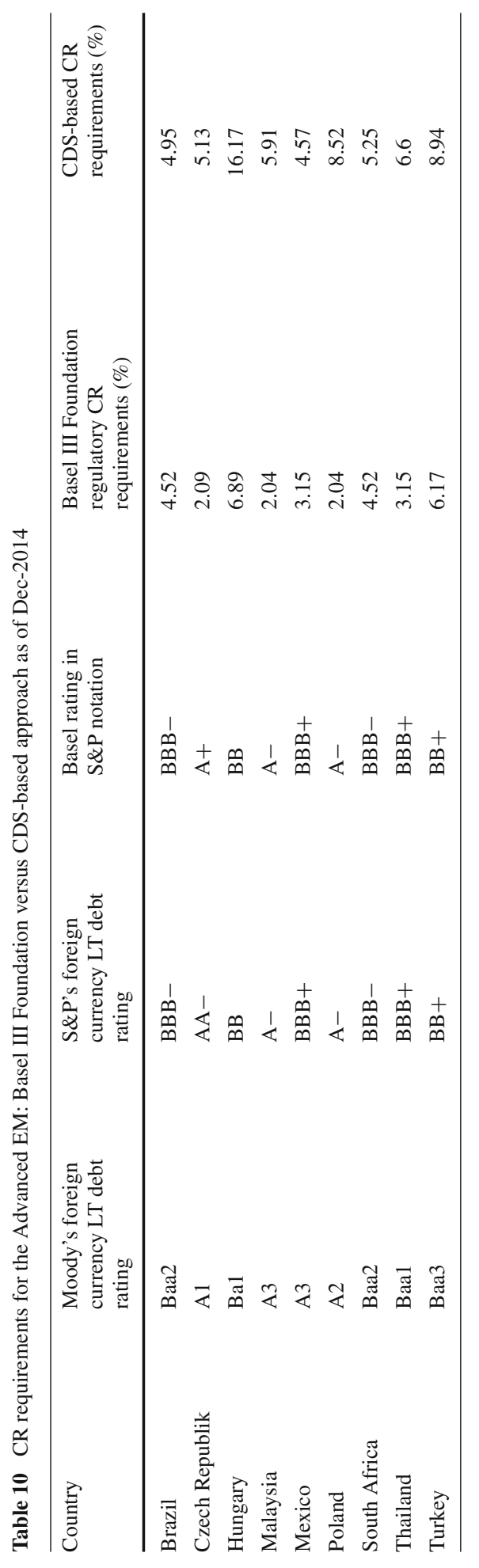




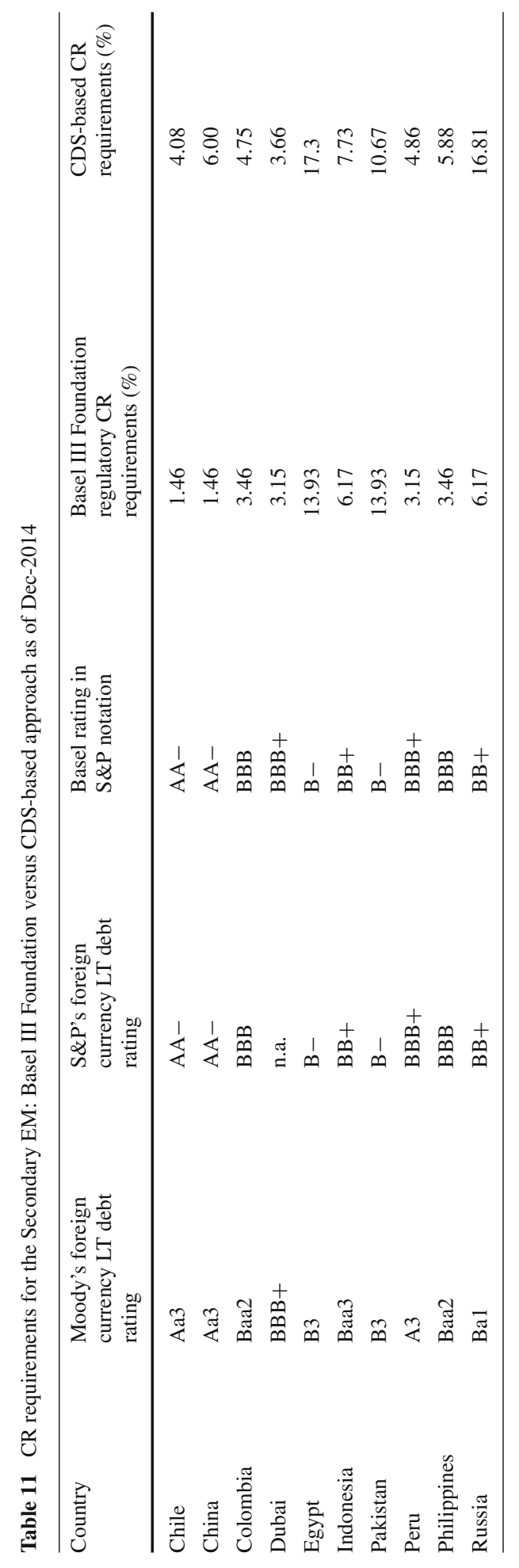




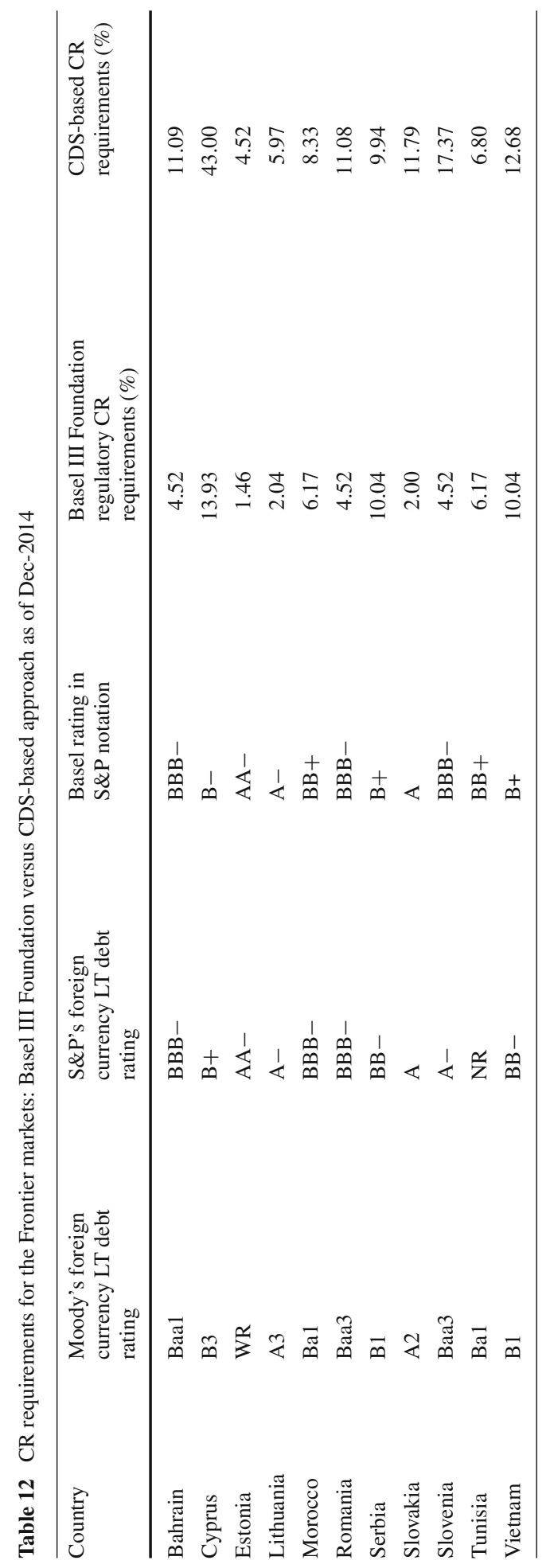




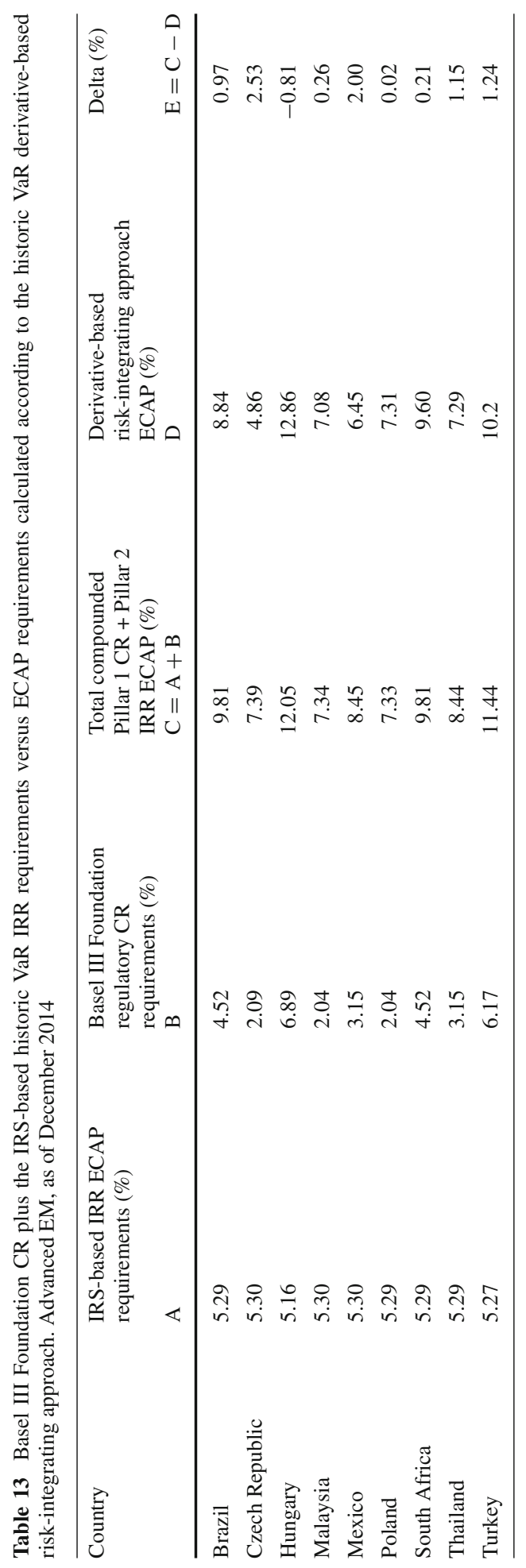




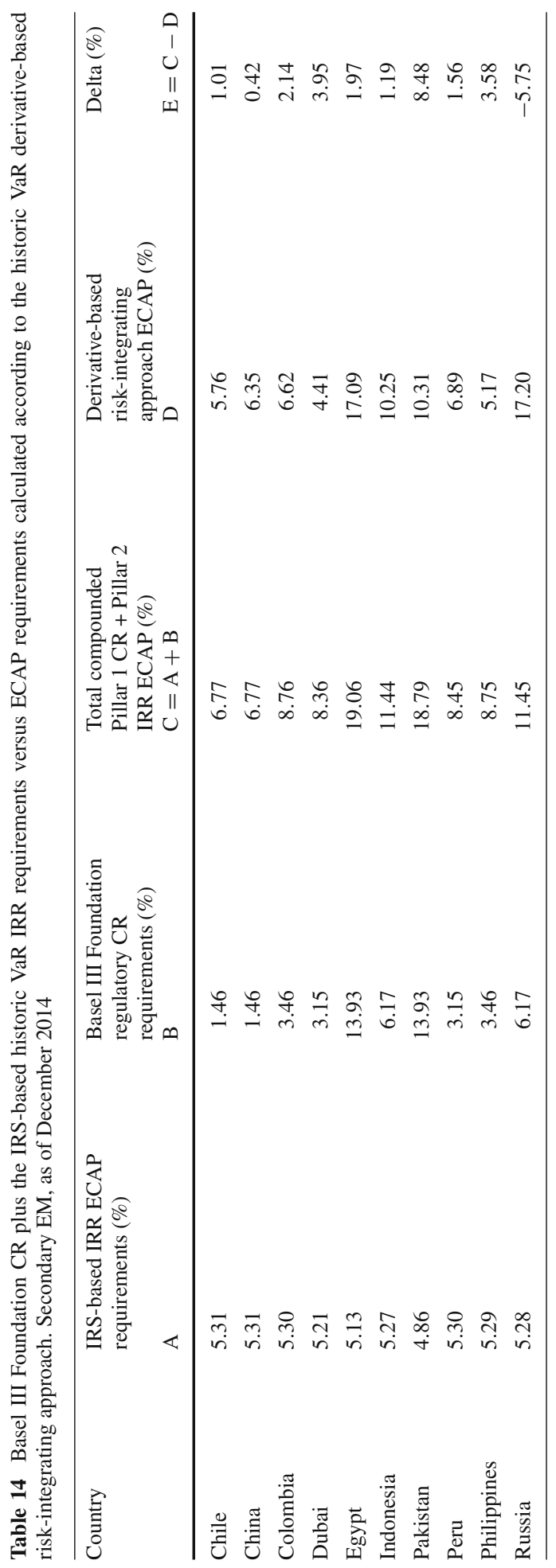




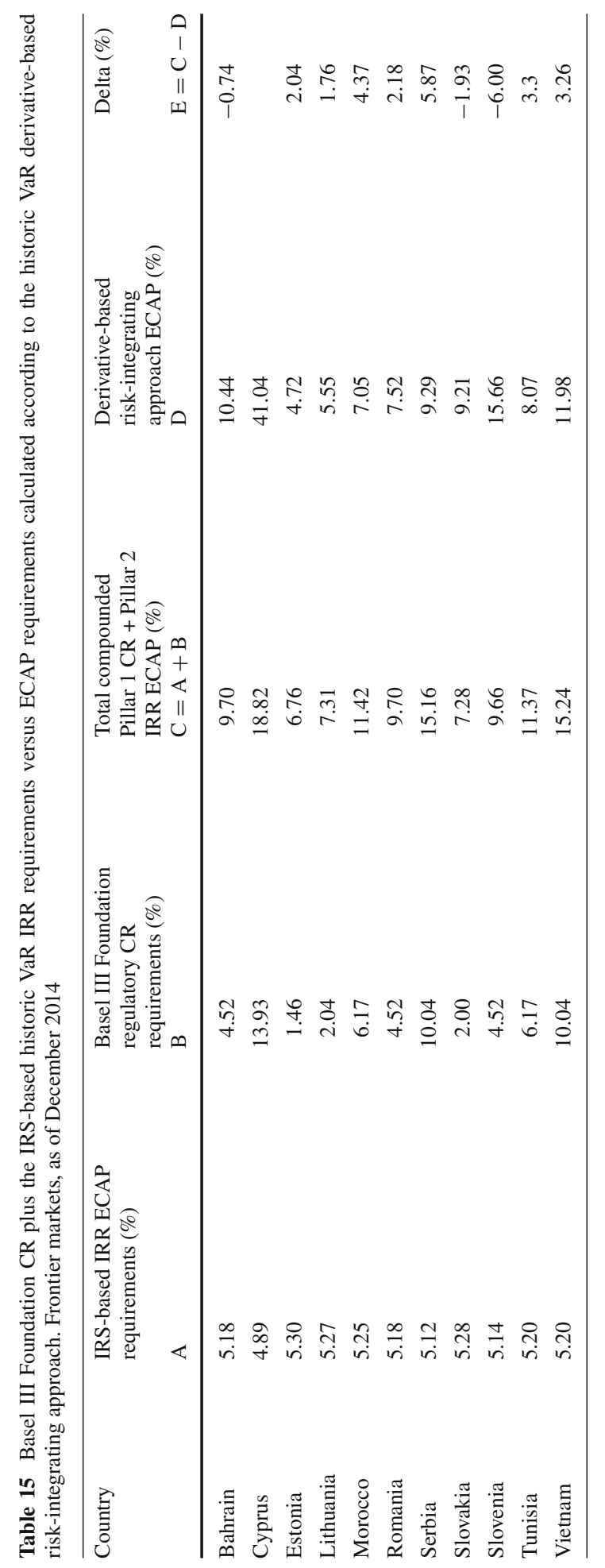




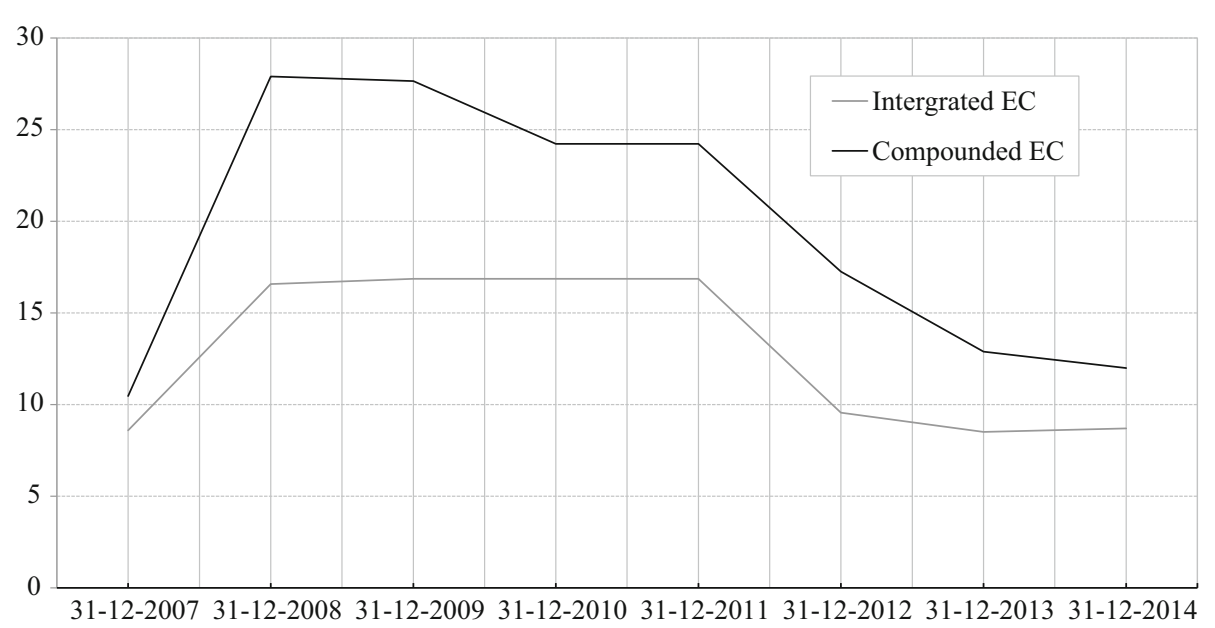

Fig. 4 Comparison of derivative-based ECAP under integrated versus segregated approach; 5Y long VaR analysis for year-ends between 2007 and 2014. Source Bloomberg, authors' calculations

For example, the 4 years long plateau-behavior of the ECAP under the integrated approach could be easily interpreted and comprehensively understood. This plateau-behavior has its origin in the fact that the VaR series used in calculations for these 4 years, all they contain the maximum yearly crisis-driven increase in credit spreads. Thus, for the four consecutive years, namely, 2008, 2009, 2010, and 2011, the percentile analyses result in the very same outcomes.

The 2007-2008 increase in the ECAP under the integrated approach is attenuated in comparison to the ECAP under the segregated approach. It is easily comprehensible taking into consideration the existence of diversification mechanisms between the IRR and CR, discussed in the previous subsections. The integrated ECAP behavior is consistent with the dynamics of the creditworthiness of sovereign EM issuers, as during the global financial crisis and its aftermath, there was observed only slight increase in default occurrences in EM sovereign debt.

\section{Conclusion}

This research addresses the ECAP quantification methodology based on an integrated derivative-based treatment of IRR and CR. We apply our approach to the EM sovereign debt portfolios. This study represents a long needed attempt to define a common basis for discussion between banking industry and financial markets regulators. We demonstrate that an integrated treatment of the IRR and CR accompanied by the analyses of ECAP-wise IR sensitivity of assets can result in an optimized ECAP figures. That is of a special importance to banks and financial institutions of EM geographies.

We find that the ECAP requirements under the integrated approach are consistently lower than the ECAP requirements quantified following the segregated approach just to CR assessment. This suggests that the hedging of downside risk could be based on augmenting exposure to the IRR under distressed economic conditions. 
We demonstrate that the ECAP-wise cross-elasticity is a function of the considered phase of a business cycle. For exposures with interest risk elasticity values below minus one the downside risk could be potentially hedged by pay-float receive-fixed IRS contracts, while the downside risk of positions with ECAP-wise elasticity above minus one could be hedged by pay-fixed receive-float IRS contracts.

Our approach potentially allows for distilling liquidity components present in yields by subtracting the CR and IRR related components from the bond yield.

Finally, we benchmark the proposed derivative-based integrated approach against the Basel III regulation using Basel II/III formula for the CR capital requirements under the internal ratings based (IRB) Foundation approach. It is shown that the proposed herein approach is consistent with the benchmark.

It serves as an additional argument that appeals for better acceptance by the Basel Committee of the joint risk treatment as an appropriate approach to assess ECAP requirements of financial institutions. Although for internal management processes banks and financial institutions in principle can use whatever risk measurement techniques they choose, predominantly only mainstream segregate risk-specific VaR approaches are employed so far in supervisory review and evaluation process (SREP) guided by regulators.

We consider our research as a piece of a promotion effort, necessary for the regulatory admittance of joint risk approaches in measuring financial institutions' exposures. Because of imperfect correlations between risks, the ECAP based on integrated treatment of constituent risks is smaller than the sum of the individual risk-specific ECAPs. In the considered herein case: $E C A P_{\text {Integrated }}<E C A P_{C R}+E C A P_{I R R}$. Thus, being unwilling to accept the benefits of inter-risk diversification in setting capital requirements, bank regulators, in their attempt to cover potential unidentified risks, systematically overplay the identified risk exposures faced by financial institutions.

Although this research addresses a regulatory perspective of the IRR and CR integration relative to the EM government debt, looking ahead, we can affirm that the applicability of the integrated derivative-based approach is considerably wider than the sovereign debt of EM. Thus, further research in this field is highly desirable for positively impacting overall efficiency of financial system as it potentially allows banks and financial institutions to improve their risk assessment and ECAP management, while unleashing capital which could be used to further increase financial fueling of the economy.

Acknowledgements Financial support by FCT (Fundação para a Ciência e a Tecnologia), Portugal is gratefully acknowledged. This article is part of the Strategic Project (UID/ECO/00436/2013).

\section{References}

Alexander, C. (2008). Value-at-risk models. London: Willey.

Alessandri, P., \& Drehmann, M. (2010). An economic capital model integrating credit and interest rate risk in the banking book. Journal of Banking and Finance, 34(4), 730-742.

Basel Committee on Banking Supervision (BCBS). (2011). Basel III: A global regulatory framework for more resilient banks and banking systems. http://www.bis.org/publ/bcbs189.pdf

Basel Committee on Banking Supervision (BCBS). (2016). Interest rate risk in the banking book. http://www. bis.org/bcbs/publ/d368.pdf

Boulkeroua, M., \& Stark, A. (2013). On the determinants of the sensitivity of the yield spread of corporate bonds to changes in the level and slope of the yield curve. In N. Apergis (Ed.), Proceedings of the IV world finance conference (pp. 118-167).

Chen, R., Cheng, X., \& Wu, L. (2013). Dynamic interactions between interest-rate and credit risk: Theory and evidence on the credit default swap term structure. Review of Finance, 17(1), 403-441. 
Chen, R., Yang, L., Wang, W., \& Tang, L. (2015). Discovering the impact of systemic and idiosyncratic risk factors on credit spread of corporate bond within the framework of intelligent knowledge management. Annals of Operations Research, 234, 3-15. doi:10.1007/s10479-014-1727-y.

European Parliament. (2013). Regulation (EU) No. 575/2013. http://www.eur-lex.europa.eu

FTSE International Limited. (2014). FTSE country classification process. http://www.ftse.com

Fuerst, F., McAllister, P., \& Sivitanides, P. (2015). Flight to quality? An investigation of changing price spreads in commercial real estate markets. Studies in Economics and Finance, 32(1), 2-16.

Gubareva, M. (2014). Financial instability through the prism of flight-to-quality. Saarbrucken: Lambert Academic Publishing.

Gubareva, M., \& Borges, M. (2016a). Typology for flight-to-quality episodes and downside risk measurement. Applied Economics, 48(10), 835-853. doi:10.1080/00036846.2015.1088143.

Gubareva, M. \& Borges, M. (2016b). Binary interest rate sensitivities of emerging market corporate bonds. In Z. Serrasqueiro, F. Sardo \& J. Leitão (Eds.) Proceedings of the 9th Finance conference of the Portuguese finance network (PFN) (pp. 1685-1718). Covilha: Universidade da Beira Interior. ISBN: 978-989-654300-6

International Monetary Fund. (2015). Global financial stability report, October 2015: Vulnerabilities, legacies, and policy challenges - risks rotating to emerging markets.

International Monetary Fund. (2016). Global financial stability report, April 2016: Potent policies for a successful normalization.

Jermann, U. \& Yue, V. (2013). Interest rate swaps and corporate default. Working paper series No. 1590. European Central Bank.

Landschoot, A. (2008). Determinants of yield spread dynamics: Euro versus US dollar corporate bonds. Journal of Banking and Finance, 32(12), 2597-2605.

Lin, E., Sun, E., \& Yu, M. (2016). Systemic risk, financial markets, and performance of financial institutions. S.I.: Financial Economics. Annals of Operations Research, 1-25 doi:10.1007/s10479-016-2113-8.

Moody's. (2015). Annual default study corporate default and recovery rates, 1920-2014. https://www.moodys. com/researchandratings.

Neal, R., Rolph, D., Dupoyet, B., \& Jiang, X. (2015). Interest rates and credit spread dynamics. The Journal of Derivatives, 23(1), 25-39.

Standard \& Poor's. (2015). Default, transition, and recovery: 2014 Annual global corporate default study and rating transitions. http://www.standardandpoors.com/ratingsdirecty.

Tang, D. Y., \& Yan, H. (2010). Market conditions, default risk and credit spreads. Journal of Banking and Finance, 34(4), 743-753.

Zimper, A. (2014). The minimal confidence level of Basel capital regulation. Journal of Banking Regulation, 15(2), 129-143. 